\title{
Analysis on the Study Failure of Students in China Today
}

\author{
Shufang Qu ${ }^{1}$, a , Hun Lee Koay ${ }^{2, b}$ \\ ${ }^{1}$ School of Business, Malaysia University of Science and Technology, Malaysia \\ ${ }^{2}$ School of Business, Malaysia University of Science and Technology, Malaysia \\ ${ }^{a}$ qu.shufang@phd.must.edu.my, bhlkoay@must.edu.my
}

\begin{abstract}
Selection is one function of education, when some students can not endure the failure. The students fail because of their poor learning methods, learning attitudes and learning behaviors. Teachers do not clarify the functions and purposes of exams and homework, so the students do not like the exams and the homework. The criticisms from parents and teachers are not serious. It is understandable that some students fail in study. If the failure of some students is unavoidable, people should do more to lessen the failure and give the students more success.
\end{abstract}

Keywords: Failure, Education, Success.

\section{Introduction}

Education is becoming more and more important. Education has some functions, for example, selection which makes some students fail in study. The failure of some students is unavoidable because of the selection. Due to the multi-intelligent system of everyone, it is not surprising that some students fall behind. Many parents force their children to study well and they try many ways to make their children keep up well with others including make-up lessons outside school.

Education fulfills the task of social stratification and makes the society equal with everyone's hard work. Why does study failure come into being? Study failure is unavoidable because the functions of education, for example, selection, competition, potential abilities, different teachers and different family backgrounds. All these phenomena make students different from others. Facing the failure, the students are always scolded, criticized by parents and teachers. This state makes the students even worse. The poor scores are already the symbol of failure if there is no criticism from parents and teachers. Because of the criticism, the students' feelings and emotions become worse and they endure some degree of failure feelings.

Everyone has potential abilities although the abilities differ from one to another. The differences make the teaching very difficult because of the multi-intelligence of each person. It is different to cater for all tastes. With different potential abilities, many students fail because maybe they are not suitable to the cramming teaching which receives a lot of criticism and censure. With many years of history, China has formed one principle, that is, teaching students in accordance of their aptitude. This principle is always workable and successful.

The environment plays an important role in education where everyone has his special potential abilities in study. However, when someone has been deprived of the learning environment, they will also fail in study. Without their learning environment, the potential abilities will not be practised and improved, so the potential abilities will be forgotten and stopped. We can make a conclusion that everyone's progress is the combination of one's potential abilities and the learning environment which are both important in the progress of human being. The potential abilities must be inherited and be unique. Without the genetic inheritance, everything is impossible. [1] The competitions and the theory of the survival of the fittest explain why some people fail and why some people succeed. The potential abilities and the environment make human being exist and progress.

The progress of everyone must be the development on the basis of predecessors, who make the foundation for the human being. The progress of human being must be innovation based on the achievements of the predecessors. The human being must study and learn the existing knowledge based on his talents and the human being must be both inherited and innovative to fulfill the great tasks and the causes he must fulfill. [2] If the potential abilities and the environment are not combined well and if the inherited abilities and innovation do not achieve, the failure of study will come.

\section{Literature Review}

\subsection{Abraham Harold Maslow's Five- level Needs}

Maslow said there exist 5 levels of needs, that is, physiological needs, safety needs, love and belonging needs, esteem needs and self-actualization. The 5 levels of needs are fulfilled by the realization of low levels to high levels. [3]

\subsection{Pygmalion Effect (Rosenthal Effect)}

The Pygmalion effect shows how our expectations can really matter. The research is successful and the Pygmalion effect or Rosenthal effect has achieved great success in every level of schools, from low levels to high levels. The teachers' expectations to the students are so great that the ordinary people can make great progress if they are praised or correctly evaluated.

\subsection{Skinner's Behaviorism Theory}

Skinner's famous behaviorism theory has some disadvantages but his reinforcement theory is really powerful and reaches great attention. With this theory and method, animal training and people education can be explained and reach to a new high field. [4]

\subsection{Self Efficacy Theory}

People's success can belong to their devotions and 
contributions to their courses. If people have high levels of self efficacy, they are tend to have more success. But if people's sense of success is low, in this way, people can achieve lower success. That is to say, self efficacy determines people performances in jobs or in vocations and in school studies. [4]

\subsection{The Theory of Learned Helplessness}

Why is this word "learned" used? It shows that the sense of helplessness is acquired or learned. It is not inherited by people but it can be learned from other people but it can be learned from other people or from other fields. The sense of learned helplessness is so great that it makes many clever and intelligent students fail in their studies.

\subsection{Rogers' Humanistic Theory}

Rogers' humanistic theory pays attention to the individualism, self-esteem, expectation, and interest. Rogers thought that people have inherited desires and potential abilities for learning, which can be released in suitable atmosphere. He thought that the tasks of teachers are to provide students with learning methods, and at the same time the teachers are promoters for the progress of students.

\subsection{John Dewey's Theories}

John Dewey was one of the most powerful and influential researchers of this century. His research of "doing while learning" makes the progress of students successful and wonderful. His methods make the world different. Dewey thought "education is life", "education is progress", "education is the reform and change of experience. With Dewey's researches and methods, education in the world has come to a new age. [5]

\section{Discussion}

\subsection{The Disadvantages of Exams and Homework}

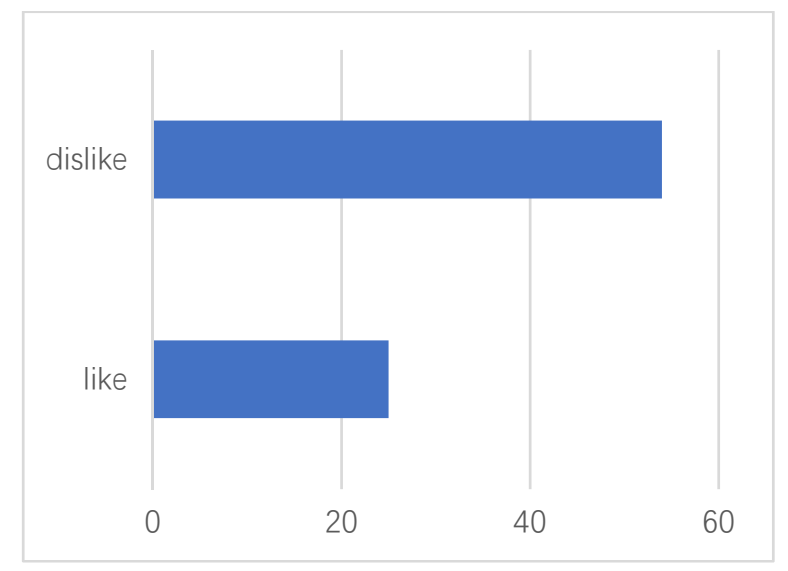

Figure 1. Do you like exams?

From the survey, we can see the students do not like exams.so the examination-oriented education will always be a failure. The examination-oriented education system will endanger the students' health. The exams give students a lot of pressure which challenge the students' psychological endurance. The examination-centred system will fail. We should have this idea in mind, that is, the purposes of examinations are to check the implementation of difficulties, the key points of learning and also all the knowledge that is learned. An exam is just a procedure of teaching. Exams are tools and not aims or objectives. If the exams are the aims, these aims must be harmful to students' health. An exam is a process and a procedure which tests the mastery of knowledge by the students and the cognitive progress. It tests whether the students' learning methods, learning attitudes and learning behavior are right or not.

Why do students dislike exams? I think that is because teachers do not explain the functions and the purposes of exams and they only make exams the method to increase the students' learning pressure. Exams are just one of the methods to check up teaching, so the students should not fear them, instead, they must consider exams to be beneficial in checking the mastery of knowledge. The purposes of exams are not intended to classify students into several groups and are not intended to select students. The college entrance examinations are a kind of tests which test whether the students have the ability to enter the senior level of learning organization, of course including knowledge and skills. If the students have not formed good learning habits and learning behavior, the students are doomed to failure. The college entrance examinations are a kind of selection.

\subsection{What Are the Advantages of Multiple Teaching?}

Many researchers think that multiple teaching can increase the efficiency of teaching because the levels of the students are the same. The multiple teaching method gives the parents and students some pressures which become one of the motives, so that the education of China can be successful. The whole society pay much attention to education, knowledge and learning. The emphasis the parents give the education is the guarantee of successful Chinese education.

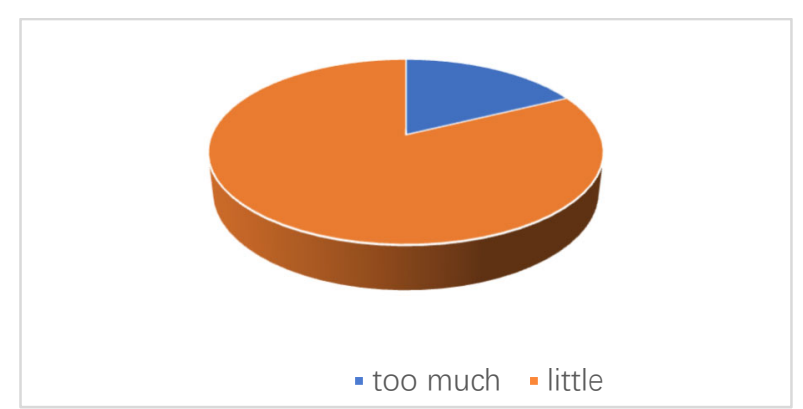

Figure 2. Parents' criticism



Figure 3. Teachers' criticism

From the survey result, we find the criticisms from parents and teachers are not severe. The students think maybe because they are teenagers, the parents dare not scold them. Maybe the teachers and parents do not consider criticism as a useful method of nurturing and there are already some reforms in teaching method in schools. Criticism has many bad effects which are disliked by many people. The inspirational 
education is effective, at least gives a kind of way or methods to succeed.

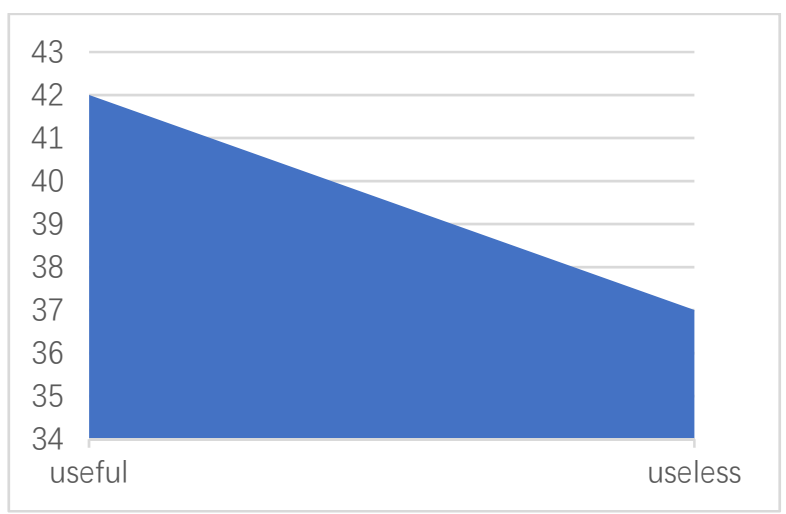

Figure 4. Inspirational education

A. Why don't students like exams or homework?

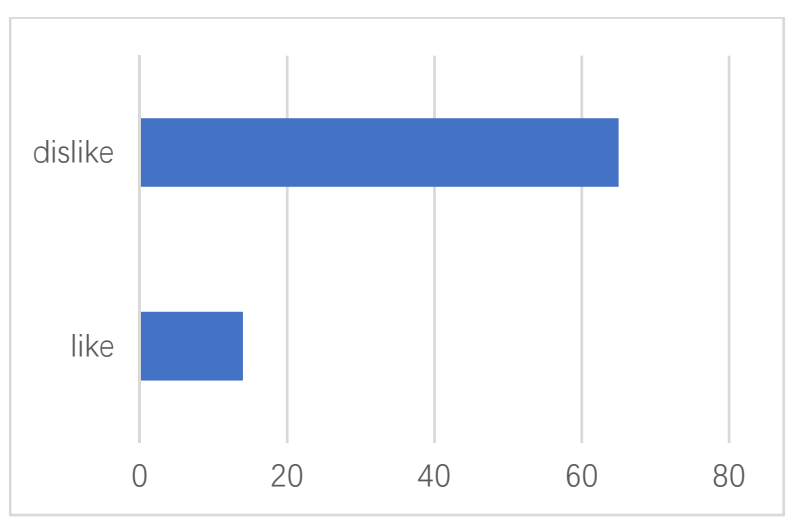

Figure 5. Do you like homework?

It is understandable that students do not like exams because the scores are too exciting and bad exam scores are a big hit to the students' confidence. It is said that failure is the mother of failure and success is the mother of success. The success can promote students' further study while the failure can make them lose everything. No one is the "ever-victorious general" and everyone must endure the failure. Why don't the students like homework because teachers do not clarify the functions of homework to students. The homework can realize the high efficiency of big classes system. For the high school students, it is impossible to have no homework. The reason why the students don't like homework is that they do not know the importance of homework and they also think exams are the aims of study, therefore, the students in primary, secondary and high school stage should gradually form the habits, methods and attitudes of learning to foster students life-long learning abilities and behaviors.

\subsection{What Causes Study Failure?}

The reasons are various, mainly the students, the teachers, parents and the society reasons. Teachers can make students successful but these kinds of teachers are not enough to meet the needs of the poor students, especially in some poor schools where the teachers' professional quality is poor and result in poor fertility phenomenon and Matthew effect phenomenon. It is hoped that the whole society realize the importance of equal education and give much attention to the polarization. The Matthew effect phenomenon should be stopped. What is Matthew effect? The Matthew effect refers to eccentric preference which faces only some students, but not all the students. This method is being stopped by modern educational system. The way to succeed for the teachers is to improve their knowledge, their teaching methods and improve their moral standard in order to improve teaching better and better.

\section{Conclusion}

Why do students fail in study? The reasons are:

They don not have good learning habits, learning methods and learning attitudes. Their fear of exams and homework shows they are weak in study and they have no good learning methods because exams and homework are just tests to see if the students have grasped the knowledge or not. Exams and homework are necessary and can not be omitted.

The students have low levels of senses of achievements in study, so parents and teachers should give students more appraisal to stimulate their learning. From the survey, we can see although the students receives a little criticism, the students are still lack of appraisal and stimulation.

In high schools, the students should form good learning methods, attitudes and behavior. Exams and homework are just methods and the necessary steps for learning. The teachers should tell the students the importance of exams and homework to let the students face the challenge in study bravely. Exams and homework are challenges to the students' knowledge, determination, learning methods, learning attitudes, etc. If the students are afraid of exams and homework, it shows the students are weak and need good guidance to face the examinations bravely.

The stresses and the setbacks the students endure must be moderate, or they will endanger the healthy states of students. If students are afraid of examinations and homework, it shows the senses of achievements are low and need improvement.

Are the exams and homework the causes of students' failure in study? No, but the learning habits, learning methods, learning attitudes and the teachers' poor teaching and management. It is hoped that all the students will face the challenges bravely and succeed in study. What makes the students fail in study? Selection is the answer.

A failure teacher also brings in a lot of failure students because the failure teachers are lack of a lot of good qualities.

\section{References}

[1] Peng Huamin, 2014,Human Behavior and Social Environment, Higher Education Press, Beijing.

[2] Liu Haimin, 2011, Principle of Pedagogy, Higher Education Press, Beijing.

[3] ZhaoFucha,2013,PrimaryEducationManagement,Beijing Normal University Press, Beijing.

[4] Xie Youru,2016,Principles and Methods of Instructional Design, Higher Education Press, Beijing.

[5] Li Xueqin, 2006, What is Pedagogy, Peking University. Press, Peijing. 